\title{
The inspiration of Chinese literati painting art to modern graphic designs
}

\author{
Ping Leng \\ Harbin University of Science and Technology Rongcheng Campus, Rongcheng 264300, China. \\ 474288172@qq.com
}

Keywords: Man-of-letters painting, format design, the Chinese cultural renaissance.

\begin{abstract}
Man-of-letters painting, also known as "Scholar-official painting ", "scholar-official drawings ", are the paintings with literary taste in the painting, revealing literati outside the painting, The have unique "elegant" and are different from craftsmen painting and House body draw yuanti drawing, develop a school of their own. Traditional Chinese man-of-letters painting in get the creative application in the modern format design, which are mainly embodied in the following three aspects: use paintings to express meanings, articles and drawing match harmonily, points/lines/ face and other forms language processing rhythm, the pursuit of simplicity, using white as blank, the spirit of heaven, with both form and meaning. Book binding design refers to the surface cover design, but it is a process of putting books from planarizartion to the stereoscopic, he covered the concept design creativity, artistic thought, technical approach, and is mining and recreation of the culture to some extent.
\end{abstract}

\section{The Introduction}

The application of man-of-letters painting in modern graphic design, refers to refine the literati spirit form traditional Chinese painting art forms and literati spirits, and adopt the reasonable application, such as posters, books, brochures and other media, based on its content in order to draw moral and express design thoughts. Traditional Chinese literati painting, focus on the performance of artistic conception and emotion spread, false or true complement, so as to blend in with nature as a whole, to reach metamorphose world of expressing emotion by objects, expressing meaning by emotion by . Conveying intention is the most important goal in modern plate design.

1. The enlightenment of the foreign traditional painting and calligraphy to modern design. To take Japan for cases, Japan painting art, taking Ukiyoe as the representative has produced far-reaching effect on Western painting and modern design development in 19th century late. Impressionist, and new art movement draw nutrient from Japan painting art, non-symmetric composition technique, curve using, exaggerated line drawing technique, planarity Visual image, produced far-reaching effect on modern Western design development. Japan contemporary graphic design still retains the Japan traditional forms painting language, reflecting Japanese spiritual life.

2. The application of Chinese traditional culture in design. Rise of Chinese design power, enhancement of Chinese confidence, culture circles, art circles, design circles, and the voice of Renaissance of Chinese traditional culture can be heard without end. The five thousand years of Chinese civilization, fine arts, arts and crafts are like a bright pearl embedded in the land of China. Times change, dynasties change make people ignore every single artworks containing the spirit of the times, reflecting its people's living and cultural, as well as the originality of the cultivation of the craftsmen. However, unlike other art, man-of-letters painting, distinct from court painting, secular painting, pay more attention to the painter's spirit level, and separate from the techniques used. This 
painting greatly focus on conception, abandon the elaborate coincidence and technique, and conform to the spirit of contemporary modern design more.

\section{Chinese traditional aesthetics wisdom that Chinese literati painting and calligraphy art contain}

1. Using paintings to express meaning. Literati painting is an important genre of raditional Chinese painting. literati and officialdom (in feudal China) regard the painting related to spiritual regulation means, the creation to these painters, play just a effect of spirit eliminating . In this case, not driven by material, not being method of micro, using the simplest tools, most general language, to convey our deepest feelings, has become an inevitable choice in the creation. So-called literati painting, have unique "elegance" which is different from craftsmen painting and body painting in the traditional painting, and have develop a school of their own. They stressed personality performance and combination of poems, books, paintings and other artistic, the authors mostly have deeper and more comprehensive culture scholar. literati paintings are painted with literary taste, revealing literati thoughts outside painting. They do not parallel with three Chinese painting: landscapes, flowers and birds and people. For Zheng Banqiao's explanation of literati painting, he said "not studying the fine art work, you must see the thoughts of the literati outside the painting."

2. The literary aesthetics in literary aesthetics paintings art. The literary Painting is an integrated art, scientific literature, calligraphy, painting and seal cutting art as a whole, is the embodiment of artist's multifaceted cultures, especially have close relationship with calligraphy. The combination of points lines and strokes in the calligraphy is not only the basic elements of constituting art, and is an important and independent aesthetic appreciation value objects. The quick slow light heavy of wielding pen, dot density thickness forming a unique rhythm and rhyme, must be able to reflect the artist's specific mood, temperament and personality in the creative process, and combine these with the spirit and shape of things, to be perfectly skilled, pneumatic consistency, although the mark is broken but the airflow is connected, the pen is not thoughtful but the meaning is thoudhtful.

\section{Analyze the visual language of man-of-letters painting from modern graphic designs.}

1. Graphics language. Man-of-letters painting pays attention to alike in spirit, using abstract graphic language and simple calligraphy to convey proud and spirit of intellectuals. Wintersweet, orchid, bamboo, chrysanthemum are the most common graphic language in literati paintings, which are uesed to highlight and respent the intellectuals's spirit world. Painters will stress the charm of their painting by abstract freehand brushwork, using the perceptual, implicative and metaphor technique to inspire people's association and express their inner emotional content and ideas. The specific clear symbolic image shows the contents of the layout, which is consistent with painting's content. That is to say the symbolic image is associated with the nature of things as one.

2. Verbal language. Chinese word itself is the best art of graphic language, Beijing's Olympic bid logo, designed by the famous designer Mr. Chen Shaohua, can be said to be a successful example of the use of calligraphy elements into design. With the unique calligraphy and painting freehand brushwork technique in traditional Chinese painting, this logo, as if a man is performing taijiquan, not only combines the malapropism in calligraphy with vigorous and effective brushwork successfully, but also perfectly expresses the understanding of the Olympic spirit in China and conveys the spirit of Chinese traditional sports culture. In the literati paintings, Chinese literati 
attaches great importance to the words in the painting and the combination of calligraphy and painting, using basic graphics language such as, point, line and plane in the layout of pictures.

\section{Analyze the language forms of man-of-letters painting from modern graphic designs.}

1. General language of point, line and plane. The basic elements in modern graphic designs is point, line and plane, and those three elements can be found in the traditional Chinese ink painting. For example, in a Chinese Landscape Painting, it has swarms of continuous mountain, waterfall rivers run through the mountains, poets and painters sit beside rivers, chatting and drinking tea. Planes, lines and points combine with each other in the painting, creating a feeling that the picture is flowing.

Line is known as ""Calligraphy and Drawing Having the Same Roots"in China, either book or painting uses the same tool. Bank, Yunbi skills such as the same, Chinese calligraphy is "line-defined" and Chinese painting has always been a "line modeling".

Pionts, cun lines and points. The painter uses a shorter, smaller, lighter cun lines and points in distant view, a long, heavy cun-point in close-ups while a strong short-term and points in shady part of the mountain. Various sects of mountains painted in overlapping method, the artists use these methods to make different depth of the mountains.

Plane, Chinese scholars prefer to express the artistic conception through surfaces, mountains, bamboo forests, waterfalls,all those planes created by thick lines gethering with thick points.

2. The level of language. On color and ink painting, the literati painting pays more attention to the use of ink, dividing ink into five colours. The reason why literati painters take serious of ink but light color is directly related to traditional Chinese painting art concepts and aesthetic ideas. That means the creative purpose of traditional painting is not to faithfully reproduce the appearance of things, but its highest artistic pursuit is to reveal intrinsic charm of things. Initiative pursuit of Literati painters in art is based on this purpose, and the formation of a national unique aesthetics that abandon the appearance of things, take in the intrinsic charm of things, stress Plainness after stress, back to nature, large or destruction. Using ink to distinguish different levels, reflect the distance, highlight the figure-ground relationship, can help to enhance painting's subject.

In Chinese ink painting, especially in landscape painting, painters will leave an empty space and pay attention to artistic conception, giving some speace to the viewers to imagine. The figure painting is more emphasis on charm with a slight deviation anatomical proportions, a less rigorous structure, but full of flavor, giving a spiritual consistency to its viewers.

Literati painting composition rarely uses symmetrical approach, generally achieve harmony and unity of the screen through keeping a balance between calligraphy and painting. The picture uses diagonal composition, or stresses on one side, and then uses the calligraphy to achieve visual balance, more lively and interesting.

3. Handling the empty space. Traditional ink painting not only has a unique artistic technique, and also has taken in something good of modern layout designs, such as the means of composition. Marginal landscape is known as a Chinese painting composition style. As a saying, one is of ten the corner of the back mountain water, Marginal landscape is partial to paint at edge, leaving a large empty space, white but not empty. Ma Yuan, Xia Gui, lived in Song dynasty are the representative landscape painter, and Xia Gui was known as “Xia Banbian”. Both of their Marginal landscape not just a highly refined of art, but also the traditional landscape development. Ming Dynasty, Cao Zhao talked about composition style of Marginal landscape in "Gegu Yaolun": the wounderful combination of "black" and "white", "virtual" and "real" makes the empty speace filled with magic of tension and beauty of artistic conception. 
"Knowing how to leave a empty space and using ink" is an important theory of Chinese painting which, to a great extent, is a skill on layout and composition, applying to modern graphic designs. To highlight the theme, painters must leave a large empty space so that he can emphasized what he want to express by the image information content, forming a visual focus. Visual focus is not in the center of the layout but focus on the information and its position is arbitrary, wherever is Ok. For example, in Ma Yuan landscape painting, visual focus on landscape naturally, rather than the empty speace. For further research, with one person or a boat in the blank of the landscape painting can help to create a visual focus, distinguish different levels of outlay and attract more interest of admiring from its viewers.

\section{Conclusion}

With modern design idea appreciating the traditional Chinese literati paintings is to draw nutrients from the traditional culture, to better learn the traditional art, to provide a wealth of theory and practice. We can not only draw lessons from the form of traditional literati paintings, but also learn the spirit of the ancient Chinese intellectuals. We can know literati painting painting original purpose which is express the ideas through painting. Meanwhile, most important criterion to consider the modern layout design is excellent enough is whether the painting expresss its idea appropriately. In this sense, literatipaintings has important practical significance to the modern graphic designs.

\section{References}

[1] Yanjing Xia. Design History of China [M]. Liaoning People's Publishing House, pub. Jun.2001. [2] Daiqiang Jin. Graphic Design Practice [M]. Shanghai Literature and Art Publishing House, pub. 1 Dec. 2005.

[3] Shouzhi Wang. The History of Modern Design [M]. China Youth Publishing House, pub.Sep.2002.

[4] (British) Gavin Ambrose. The Graphic Design [M]. China Youth Publishing House, pub. Dec.2011. 